\title{
Pigmentation Effects of Kaliziri Standard Extracts on Melanocytes, C57BL/6 mice of Hydroquinone- Induced and Guinea Pigs of Hydrogen Peroxide- Induced Hyperpigmentation Model
}

\section{Deng Zang}

Xinjiang Technical Institute of Physics \& Chemistry

\section{Zulipiya Maimaiti}

Chinese Academy of Sciences

Nuramina Mamat

Chinese Academy of Sciences

\section{Xiaoling Ma}

Chinese Academy of Sciences

Haorong Li

Chinese Academy of Sciences

\section{Xueying Lu}

Xinjiang Technical Institute of Physics \& Chemistry

Ablajan Turak

Xinjiang Technical Institute of Physics \& Chemistry

\section{Yuqin Luo}

Xinjiang Technical Institute of Physics \& Chemistry

Haji Akber Aisa ( $\nabla$ haji@ms.xjb.ac.cn )

Xinjiang Technical Institute of Physics \& Chemistry

\section{Research Article}

Keywords: Kaliziri standard Extracts, melanogenesis, p38 MAPK, vitiligo model, skin-darkening effect

Posted Date: October 1st, 2021

DOl: https://doi.org/10.21203/rs.3.rs-870219/v1

License: (c) (1) This work is licensed under a Creative Commons Attribution 4.0 International License. Read Full License 


\section{Abstract}

Background: Vitiligo is a depigmentation disorder characterized by losing functional melanocytes, leading to skin and/or hair depigmentation. Kaliziri (Vernonia anthelmintica (L.) Willd) seeds have been traditionally used to treat pigmentation disorders in Central Asia. The extracts of these seeds increased melanin content and tyrosinase activity and upregulated melanogenesis-related proteins in B16 melanoma cells. We isolated the main active compound Kaliziri standard Extracts (encoded as CAM-Y7) from the Kaliziri seeds in a previous study. Our goal was to reveal whether CAM-Y7 promotes melanogenesis in melanocytes and restored pigmentation in animal models of vitiligo.

Methods: Herein, we analyzed the melanogenic effects of CAM-Y7 on melanocytes and the skin pigmentation of hydroquinone (H.Q.)-induced mouse model and hydrogen peroxide $\left(\mathrm{H}_{2} \mathrm{O}_{2}\right)$-induced guinea pig model of vitiligo.

Results: CAM-Y7 promotes Melanogenesis up-Regulation MITF-induced Tyrosinase Expression via p38MAPK signal pathway in melanocytes. Oral administration of CAM-Y7 progressively darkened the dorsal skin and hair of the C57BL/ 6 mice and guinea pigs. Lillie staining and hematoxylin-eosin staining further showed that CAM-Y7 induced melanogenesis in the epidermis and hair follicles of the animals.

Conclusion: Taken together, these results suggest that CAM-Y7 regulation of melanogenesis may be mediated by the activation of p38 MAPK and restored pigmentation in an HQ-Induced C57BL/ 6 mouse and $\mathrm{H}_{2} \mathrm{O}_{2}$-induced guinea pig models of vitiligo. CAM-Y7 might be valuable and promising therapeutic as an agent for vitiligo. Subsequent clinical experiments using are needed to verify our results.

\section{Introduction}

Melanogenesis, or the production of melanin, occurs in the melanocytes of the epidermal basal layer. The melanin granules formed in the basal layer are transferred and stored in the overlying keratinocytes ${ }^{[1,2]}$. Dysfunctional melanogenesis or the absence of melanocytes can lead to skin hypopigmentation [3]. Vitiligo is a depigmentation disorder involving selective dysfunction and destruction of melanocytes, leading to loss of melanin in the skin and hair ${ }^{[4]}$.

Tyrosinase is a crucial enzyme as it catalyzes the rate-limiting step in melanogenesis, mainly converts Levo-dihydroxyphenylalanine (L-DOPA) into L-dopachrome ${ }^{[5]}$, and deficit of tyrosinase enzyme in melanocytes, was leads to hypopigmentation disorders ${ }^{[6,7]}$. The microphthalmia-associated transcription factor (MITF) gene was melanocyte differentiation and melanin production by regulating several genes involved in pigment formation and melanocyte differentiation ${ }^{[8]}$. pigmentation-related genes, including Tyrosinase, tyrosinase-related protein 1 (TRP-1), tyrosinase-related protein 2 (TRP-2), that MITF activates promoters of these three genes ${ }^{[9]}$. Current treatment modalities of vitiligo aim at stalling further melanocyte dysfunction and inducing re-pigmentation. 
The expression and activity of MITF were regulated by MAPKs, which were key signaling molecules involved in regulating melanogenesis, including the c-Jun $N$ terminal kinase (JNK) $1 / 2$, extracellular signal-regulating kinase (ERK), and the p38 MAPK signaling cascades ${ }^{[10]}$. Previous studies have shown that the JNK and ERK stress-activated protein kinase pathways to downregulated melanin synthesis ${ }^{[11]}$. By contrast, the phosphorylation of p38 MAPK activates MITF to stimulate melanogenesis ultimately.

Vernonia anthelmintica (L.) Wild was a famous medicine for vitiligo and known as Kaliziri in Traditional Uyghur Medicine (TUM); the seeds of Kaliziri have been used to treat skin depigmentation diseases in TUM for over a century. The seed extracts promoted melanin production and tyrosinase activity and induced melanogenesis-related proteins in B16 melanoma cells ${ }^{[12]}$. In a previous study, we isolated the main active compound Kaliziri standard Extracts (encoded as CAM-Y7), including sesquiterpenoids, caffeoylquinic acids, and active flavonoid compounds $V$. Kaliziri seeds. Herein, we found that CAM-Y7 successfully accelerates melanogenesis in B16 cells, subsequently the mechanism of promoting effect on melanogenesis via p38 MAPK signal pathway up-Regulation MITF-induced Tyrosinase Expression and restored pigmentation in an $\mathrm{HQ}$-Induced $\mathrm{C} 57 \mathrm{BL} / 6$ mouse and $\mathrm{H}_{2} \mathrm{O}_{2}$-induced guinea pig models of vitiligo.

\section{Materials And Methods}

\section{Materials}

CAM-Y7 was prepared by The Key Laboratory of Plant Resource Sand Chemistry of Arid Zone, Xinjiang Technical Institute of Physics and Chemistry, Chinese Academy of Sciences: One kilo V. anthelmintica seeds was powdered and extracted twice using 12 liters of $80 \%$ ethanol/water at $80^{\circ} \mathrm{C}$, each extraction lasting $2 \mathrm{~h}$. Both extracts were pooled and filtered, and the filtrate was concentrated in a rotary vacuum evaporator to $0.1 \mathrm{~g} / \mathrm{m}$. The crude drug was then adsorbed on $2.5 \mathrm{~L}$ macroporous HPD300 resin at the flow rate of 2-bed volume per hour (BV/h), purified with 3BV of water, and then eluted with $3 B \mathrm{BV}$ of $60 \%$ ethanol/water. The eluent was evaporated under reduced pressure and dried at $45^{\circ} \mathrm{C}$ to obtain $62 \mathrm{~g}$ of the purified drug powder. And dissolved in DMSO and stored at $-20^{\circ} \mathrm{C}$ as a stock solution $(10 \mathrm{mg} / \mathrm{ml})$. L-DOPA (CAS No 59-92-7) was obtained from Generay Biotech (Shanghai, China), 8-MOP (CAS:298-81-7) was purchased from Sigma Aldrich (Milan, Italy), CCK-8 was obtained from Trans Gen Biotech (Beijing, China), RIPA Lysis buffer (AR0105-100) was obtained from BOSTER Biological Technology (Wuhan, China), BCA kit assay (PP02) was purchased from Biomed Biological Technology (Beijing, China). Antibodies against $\beta$-actin (8H10D10) and Tyrosinase (C-19), TRP-1 (H-90), TRP-2 (H-150) were purchased from Santa Cruz Biotechnology Inc. (Santa Cruz, CA, USA). Anti-MITF antibody was obtained from Abcam (Cambridge, UK). Goat anti-rabbit (BA1054), p38 (L53F8), p-p38 (Thr180/Tyr182) (28B10), SAPK/JNK (\#9252s), p-JNK (Thr183/Tyr185), ERK(L34F12), and p-ERK(Thr202/Tyr204) (E10) were purchased from Cell Signaling Technology (Danvers, MA, USA), goat anti-mouse (BA1050), rabbit anti-goat (BA1060) antibodies were obtained from BOSTER Biological Technology (Wuhan, China), interleukin 6 (IL-6), tumor necrosis factor-a (TNF-a), Tyrosinase (TYR), and monoamine oxidase (MAO) and malondialdehyde (MDA) specific ELISA kits were obtained from Elabscience Biotechnology (NJJCBIO Co., Nanjing, China). 


\section{Drug analysis}

Fifty milligrams of the sample powder were dissolved in $10 \mathrm{ml}$ methanol and filtered through $0.22 \mu \mathrm{m}$ nylon membrane microfilters (Shimadzu-GL, Japan) and chromatographically analyzed using a Shimadzu LC-2030c HPLC fitted with a photodiode detector (PDA) (Shimadzu-GL, Japan) (Fig. 1A). Reversed-phase separation was performed on a Shimadzu Shim-Pack GIST C18 column $(4.6 \times 250 \mathrm{~mm}$, $5 \mu \mathrm{m}$, Shimadzu-GL, Japan) at $35^{\circ} \mathrm{C}$. The mobile phases consisted of (A) $0.1 \%$ phosphoric acid in water and (B) acetonitrile. The sample was injected ( $5 \mu$ injection volume) onto the column and eluted at 1 $\mathrm{ml} / \mathrm{min}$ flow. The fractions were detected using U.V. light at $210 \mathrm{~nm}, 254 \mathrm{~nm}$, and $330 \mathrm{~nm}$. Quantitative analysis was performed using HPLC.

\section{Cell culture}

Experiments were conducted in B16 cells (B16, Cat\# TCM2), which were cultured in DMEM (Gibco Life Technologies, Waltham, MA, USA) supplemented with 10\% FBS (Thermo Fisher Scientific), penicillin G $(100 \mathrm{U} / \mathrm{mL})$, and streptomycin $(100 \mu \mathrm{g} / \mathrm{mL})$ (Gibco-BRL, Grand Island, NY, USA), incubated at $37^{\circ} \mathrm{C}$ in an atmosphere containing $5 \% \mathrm{CO}_{2}$.

\section{Cell viability assay}

Cells seeded at a density of $5 \times 10^{3}$ cells/well in 96 -well were incubated with CAM-Y7 for $24 \mathrm{~h}$. Then the culture medium was replaced with the CCK-8 solution $(10 \mu \mathrm{l})$, and the cells were further cultured for $2 \mathrm{~h}$ at $37^{\circ} \mathrm{C}$. Plates were read at $450 \mathrm{~nm}$ using a microplate reader Spectra Max M5 (Molecular Devices company, San Diego, CA, USA). An equal volume of cells without the treatment was used as a blank control. All the experiments were repeated three times.

\section{Tyrosinase activity}

The cellular tyrosinase activity was estimated by measuring the rate of L-3, 4dihydroxyphenylalanine (LDOPA) oxidase activity ${ }^{[13]}$. briefly, the process involved culturing the B16 cells plated on six-well plates $\left(3.5 \times 10^{5}\right.$ cells per well) and treated with CAM-Y7 for $24 \mathrm{~h}$ at $37^{\circ} \mathrm{C}$. The cells were then washed with cold PBS and lysed in a PBS buffer containing $1 \%$ TritonX-100 + 1\% sodium deoxycholate. The cell lysates were centrifuged at $12,000 \times \mathrm{g}$ for $20 \mathrm{~min}$, and $90 \mu \mathrm{l}$ of this supernatant and $10 \mu \mathrm{l}$ of $10 \mathrm{mM} \mathrm{L-DOPA}$ solution were mixed and plated in 96 -well plates incubated at $37^{\circ} \mathrm{C}$ for $30 \mathrm{~min}$. The optical densities were measured at $490 \mathrm{~nm}$ using a microplate reader.

\section{Melanin contents measurement}

The melanin contents were measured using a previously described method with a slight modification [14] Briefly, the B16 cells plated on six-well plates $\left(2 \times 10^{5}\right.$ cells per well) were incubated with various (1$10 \mu \mathrm{g} / \mathrm{ml}$ ) concentrations of CAM-Y7 for $48 \mathrm{~h}$ at $37^{\circ} \mathrm{C}$. Following this, the cells were lysed in RIPA Lysis buffer and centrifuged at $12,000 \times \mathrm{g}$ for $20 \mathrm{~min}$. $3 \mu \mathrm{l}$ supernatants of the cell extracts were used to measure 
the total protein content by the BCA kit assay. Then discarding the remaining part, $190 \mu \mathrm{l} 1 \mathrm{~N} \mathrm{NaOH}$ was added at $80^{\circ} \mathrm{C}$ for $1 \mathrm{~h}$. The optical density of the supernatant was measured at $405 \mathrm{~nm}$. For the tissue melanin assays, as with previous reports ${ }^{[15,16]}$, tissue was weighed before boiling in $1 \mathrm{~N} \mathrm{NaOH}$ for $1 \mathrm{~h}$ and centrifuged at $12000 \mathrm{rpm}$ for $20 \mathrm{~min}$ discarding the insoluble materials. Following this, the optical density of the supernatants was measured at $405 \mathrm{~nm}$ and normalized to the weight of tissue.

\section{Western blot analysis}

The protein of the B16 cells was prepared as mentioned in the previous section above. All protein per lane were separated by $10 \%$ SDS-PAGE, transferred to PVDF membrane, blocked with $5 \%$ skim milk or $5 \%$ BSA, and exposed overnight at $4{ }^{\circ} \mathrm{C}$ with appropriate antibodies. Following incubation with the second antibody, the protein bands were detected using an ECL (enhanced chemiluminescence) western blotting detection kit and quantified with a Chemi Doc MP Imaging system (Bio-Rad Laboratories, Inc, Hercules, CA, USA). All experiments were performed three times.

\section{Establishment of vitiligo model and treatment regimen}

C57BL/ 6 mice and Black dorsal skin guinea pigs were supplied by the Vital River Laboratory Animal Technology Co. Ltd., Beijing (Approval ID: SCXK-(jing) 2014-0013). All animals were housed at $22 \pm 4^{\circ} \mathrm{C}$ and $50 \pm 10 \%$ humidity with ad libitum access to food and water. The animals were acclimatized for 1 week and randomly divided into six groups ( $n=12$ per group). The dorsal side of the animals was shaved a day before the experiment using electric clippers. As previously described, dorsal hypopigmentation in the mice was induced by H.Q ${ }^{17}$. Briefly, each mouse's $2 \mathrm{~cm} \times 2 \mathrm{~cm}$ depilated region was smeared with 0.5 $\mathrm{ml} 5 \%$ H.Q. (CAS:23-31-9) once a day for 50 days. $2 \mathrm{ml} 5 \% \mathrm{H}_{2} \mathrm{O}_{2}$ was topically applied once a day for 50 days to induce hypopigmentation in the guinea pigs. A control group was also included wherein the animals were smeared with distilled water for 20 days. In C57BL/ 6 mice, the vitiligo models were treated with $720 \mathrm{mg} / \mathrm{kg}$ Vitiligo Capsule (Chinese Drug Approval Number: Z12020225) as a positive group, distilled water as a model group, or $61.5 \mathrm{mg} / \mathrm{kg}, 123 \mathrm{mg} / \mathrm{kg}$, or $246 \mathrm{mg} / \mathrm{kg}$ CAM-Y7 per day by gastric administration for 30 days. The control group was given distilled water during this period. In the guinea pig, the vitiligo models were treated with $270 \mathrm{mg} / \mathrm{kg}$ Vitiligo Capsule as a positive control, distilled water as model control, or $22 \mathrm{mg} / \mathrm{kg}, 44 \mathrm{mg} / \mathrm{kg}$, or $88 \mathrm{mg} / \mathrm{kg}$ CAM-Y7 per day by gastric administration for 30 days. The control group was given distilled water during this period. The dorsal skin of the animals was photographed every 10 days for macroscopic evaluation. At the end of the 30-day treatment, blood was withdrawn retro-orbitally from the mice and the abdominal aorta in guinea pigs under pentobarbital sodium. In addition, dorsal skin samples were also cut from the animals.

\section{Macroscopic assessment}

The extent of depigmentation was evaluated in terms of the percentage of the affected area as described previously ${ }^{18}$ and scored as follows: 0 - no depigmentation (0\%), 1 - 0-10\% depigmented area, 2 $10 \%-25 \%, 3-25 \%-75 \%, 4-75 \%-100 \%$ and $5-100 \%$. The final vitiligo score of each experimental group was calculated as the average of individual mice. 


\section{Enzyme-linked immunosorbent assay (ELISA)}

The levels of interleukin 6 (IL-6), tumor necrosis factor-a (TNF-a), Tyrosinase (TYR), and monoamine oxidase (MAO) and malondialdehyde (MDA) in the mice or guinea pig sera were measured using specific ELISA kits according to the manufacturers' instructions. The absorbance at $450 \mathrm{~nm}$ was measured with the Spectra Max M5 microplate reader (Molecular Devices company, San Diego, CA, USA).

\section{Immunohistochemistry (IHC)}

Due to the lack of guinea pig-specific antibodies, IHC was performed only on murine skin. The skin samples were fixed, embedded in paraffin, and cut into $4 \mu \mathrm{m}$ thick sections. After quenching the endogenous peroxidases with hydrogen peroxide (KIT-9730-A), the sections were incubated overnight with an anti-tyrosinase antibody $(1: 50, \mathrm{sc}-20035)$ at $4^{\circ} \mathrm{C}$, followed by the peroxidase-labeled goat anti-rabbit IgG polymer PV-6001. The sections were washed, treated with DAB solution, and viewed under a microscope (Leica Microsystems, CMS GmbH DM6000B, Germany); the protein expression was determined using Image $\mathrm{J}$ software (National Institutes of Health, Bethesda, MD, USA).

\section{Histological examination}

H\&E staining was performed on skin sections as per standard protocols. The thickness of the epidermis was measured as the distance from the basal layer to the surface of the epidermis. The melanincontaining hair follicles (H.F.) in murine skin and basal cells in Guinea pig skin were evaluated by Lillie stanning. One hundred cells were observed under high magnification $(\times 200)$ (Olympus Optical Co., Ltd., Tokyo, Japan). The number of melanin-containing Hair follicles was counted.

\section{Statistics}

All results are expressed as mean \pm S.D., and statistical analysis was performed with one-way ANOVA, followed by Tukey's multiple comparisons test. Statistical analysis was performed using GraphPad Prism 6 (La Jolla, CA, USA). P values $<0.05$ were considered to be statistically significant.

\section{Results}

\section{Characterization of drug components}

According to a previous study on $\mathrm{V}$. anthelmintica, 20 compounds were identified in the seed extracts, including caffeoylquinic acids, sesquiterpenoids, and flavonoids (Fig. 1A). The structures are shown in Fig. 1B. The contents of these components were calculated by the one-point external standard method (Table 1). 
Table 1

The relative amounts of the different compounds in Kaliziri standard Extracts (CAM-Y7)

\begin{tabular}{|lll|}
\hline Number & Component & Content (\%) \\
\hline 1 & Vernodalin & 17.76 \\
\hline 2 & Vernodalinol & 1.690 \\
\hline 4 & Vernodalol D & 1.870 \\
\hline 5 & Lasiopulide & 1.040 \\
\hline 6 & Epivernodalol & 6.240 \\
\hline 7 & 3,4-O-dicaffeoylquinic acid & 1.150 \\
\hline 8 & 3,5-O-dicaffeoylquinic acid & 16.78 \\
\hline 9 & 4,5-O-dicaffeoylquinic acid & 7.010 \\
\hline 10 & 5-O- caffeoylquinic acid & 0.000 \\
\hline 11 & 3-O- caffeoylquinic acid & 0.070 \\
\hline 12 & 4-O- caffeoylquinic acid & 0.010 \\
\hline 13 & 3',4',6,7-hydroxy-flavanone & 0.540 \\
\hline 14 & butein & 0.450 \\
\hline 15 & butin & 0.350 \\
\hline 16 & sulfuretin & 0.200 \\
\hline 17 & (-)-eriodictyol & 0.120 \\
\hline 18 & Liquiritigenin & 0.010 \\
\hline Schydellarein & & 0.380 \\
\hline Hydroquinone-Induced and Guinea Pigs of Hydrogen Peroxide-Induced Hyperpigmentation model
\end{tabular}

\section{Cell viability and the melanogenic effect of CAM-Y7}

We used the CCK-8 cell viability assay to evaluate the cytotoxic effects of CAM-Y7 on B16 cells. Although B16 cells were treated with various concentrations of CAM-Y7 $(0-10 \mu \mathrm{g} / \mathrm{ml})$, they did not show apparent cytotoxic effects or an increase in cell number (Figure 2B and 2A). Next, we evaluated the melanin contents and tyrosinase activity of CAM-Y7 to determine the melanogenic effect of CAM-Y7. As shown in 
Figure2C, 2D, the CAM-Y7 increased the cellular melanin contents $(P<0.001)$ in a dose-dependent manner and showed a concentration-dependent increase in cellular TYR activity.

\section{CAM-Y7 promotes the expression of MITF and TRPs in B16}

We evaluated the expressions of TYR, TRP-1, TRP-2, and MITF, which act as transcription regulators during the melanogenesis process. CAM-Y7 treatment showed a dose-dependent increase in TYR, TRP-1, but not TRP-2, which indicated that the CAM-Y7 could stimulate melanogenesis by enhancing the expression of TYR, TRP-1. Additionally, CAM-Y7 could also increase the expression of MITF in B16 cells. These results indicated that CAM-Y7 could induce melanin biosynthesis in B16 cells via up-Regulation MITF-induced Tyrosinase Expression (Figure 2E, 2F).

\section{CAM-Y7 promotes melanin synthesis by activation of p38 MAPK}

The phosphorylation of p38 MAPK was reported to be one of the signaling pathways involved in hyperpigmentation. Therefore, western blot analysis was performed to determine ERK, p38, and JNK in $B 16$ cells in the presence or absence of CAM-Y7. As shown in Fig. 3A and B, phosphorylation of JNK and ERK in B16 cells revealed no change by CAM-Y7 treatments; the p38 MAPK levels were significantly increased after treatment with CAM-Y7 in B16 cells compared with the control group. These data indicated that CAM-Y7 treatment accelerated melanogenesis in B16 cells by regulating the p38 MAPK signaling pathway. To further confirm the p38 MAPK pathways involved in CAM-Y7-mediated melanogenesis promotion, p38 inhibitor SB203580 was used to investigate. After treatment with CAM-Y7 for $24 \mathrm{~h}$, co-treatment with $10 \mu \mathrm{M} \mathrm{p} 38 \mathrm{MAPK}$ inhibitor SB203580 at $37^{\circ} \mathrm{C}$ for $2 \mathrm{~h}$ significantly inhibited CAM-Y7 triggered melanin content and Tyrosinase activity, respectively (Fig. $3 \mathrm{C}$ ). According to these results, p38 MAPK signaling might be involved in the melanogenesis pathway mediated by CAM-Y7.

\section{CAM-Y7 restores pigmentation of murine epidermis hair exposed to H.Q.}

H.Q. induces hypopigmentation by inhibiting Tyrosinase ${ }^{[19,20]}$, which prevents the conversion of DOPA to melanin and causes melanosome degradation and loss of functional melanocytes ${ }^{[21,22]}$. The epidermal melanocytes in C57BL/ 6 mice are primarily located within the hair follicles, which lends the black color to the fur ${ }^{[23]}$. Thus, topical application of $5 \%$ H.Q. on the dorsal skin of C57BL/ 6 mice resulted in significant depigmentation of mice skin and hair. However, treatment with CAM-Y7 visibly darkened the affected region over 30 days. Compared to the H.Q. group, the CAM-Y7-treated mice had significantly lower vitiligo scores and higher melanin content in the affected area (Figure 4A,4B,4C). Continuous exposure to H.Q. also triggers DNA damage in the keratinocytes and melanocytes, resulting in considerable tissue damage. Consistent with this, topical administration of $5 \%$ H.Q. significantly thickened the epidermal stratum corneum, which was alleviated upon CAM-Y7 treatment (Fig. 4D,4G).

Furthermore, Lillie staining showed an increase in the number of melanic hair follicles in the CAM-Y7treated skin (Fig. 4E, 4H). Together, H.Q. successfully induced vitiligo in a mouse model, and CAM-Y7 reversed the depigmentation. Tyrosinase is the core enzyme of the melanogenic pathway [24], and the 
depigmentation effects of H.Q. depend on the inhibition of this enzyme. Consistent with this, the HQtreated skin showed significantly lower tyrosinase expression and level in situ than the control group (Fig $4 \mathrm{~F}, 4 \mathrm{I}, 4 \mathrm{~J})$, which matched with the lower overall skin levels of Tyrosinase in the former. CAM-Y7 treatment restored tyrosinase levels, with the hair follicles showing the highest tyrosinase expression concentration. The protective effects of CAM-Y7 eventually manifest as increased melanin production and pigmentation.

\section{CAM-Y7 restores $\mathrm{H}_{2} \mathrm{O}_{2}$-induced depigmentation of guinea pig skin}

The HQ-induced hypopigmentation model in C57BL/ 6 mice does not truly reflect the clinic-pathological state of vitiligo since it mainly affects melanin production in the hair follicles rather than skin ${ }^{[25]}$. Guinea pig skin has an epidermis similar to that of human skin and harbors numerous melanocytes.

Therefore, $\mathrm{H}_{2} \mathrm{O}_{2}$-induced depigmentation in the guinea pig can simulate vitiligo more accurately ${ }^{[26]}$. Topical $5 \% \mathrm{H}_{2} \mathrm{O}_{2}$ resulted in significant whitening of the dorsal skin and hair similar to that seen with vitiligo and was alleviated by CAM-Y7 treatment (Fig. $5 \mathrm{~A}$ ). In addition, $\mathrm{H}_{2} \mathrm{O}_{2}$ exposure significantly increased the vitiligo score compared to the control group, which was reduced by CAM-Y7 (Fig 5B). Consistent with this, the melanin content of the $\mathrm{H}_{2} \mathrm{O}_{2}$-treated regions also increased significantly following CAM-Y7 treatment (Fig 5 C).

Furthermore, $\mathrm{H}_{2} \mathrm{O}_{2}$ caused significant epidermal damage characterized by loose and thick stratum corneum and detachment of the upper epidermal layer, in addition to significant decrease in melanin particles in the basal layer. CAM-Y7 treatment significantly alleviated this cellular damage (Fig. 5D, 5F). Lillie staining further showed a significant decrease in granular melanin in the $\mathrm{H}_{2} \mathrm{O}_{2}$-exposed skin (Fig. $5 \mathrm{E}, 5 \mathrm{G}$ ), while IHC revealed lower in situ tyrosinase levels (Fig. 5H), both of which were restored by CAMY7. Taken together, $C A M-Y 7$ alleviated $\mathrm{H}_{2} \mathrm{O}_{2}$-induced depigmentation of guinea pig skin, indicating its potential as an anti-vitiligo drug.

\section{CAM-Y7 protects guinea pig melanocytes from $\mathrm{H}_{2} \mathrm{O}_{2}$-induced damage}

The induction and maintenance of vitiligo are associated with local inflammation ${ }^{27,28}$. The proinflammatory cytokines TNF- $\alpha$ and IL- 6 inhibit pigmentation, and their mRNA levels are increased in biopsies of the vitiligo epidermis. TNF- $a$ induces apoptosis in keratinocytes, resulting in the loss of melanocytes ${ }^{[29]}$. The serum levels of TNF- $\mathrm{a}$ and IL- 6 were significantly higher in the $\mathrm{H}_{2} \mathrm{O}_{2}$-treated animals and decreased following CAM-Y7 treatment (Fig. 5K,5J). Based on these findings, we surmised that $\mathrm{H}_{2} \mathrm{O}_{2}$ penetrates the stratum corneum and damages the underlying epidermal layers, triggering an inflammatory reaction that further exacerbates tissue injury. Furthermore, oxidative stress is another key mechanism of $\mathrm{H}_{2} \mathrm{O}_{2}$-induced melanocyte destruction and depigmentation [30,31] $\mathrm{H}_{2} \mathrm{O}_{2}$ also induces apoptosis in melanocytes ${ }^{[32]}$ by increasing the cellular ROS levels ${ }^{[33,34]}$. Consistent with this, the epidermal and serum levels of both MAO and MDA increased in the $\mathrm{H}_{2} \mathrm{O}_{2}$-induced vitiligo model and were 
reduced significantly by CAM-Y7 (Fig. 5L, 5I, 5M). Therefore, CAM-Y7 not only restores tyrosinase activity but also protects melanocytes against $\mathrm{H}_{2} \mathrm{O}_{2}$-induced toxicity and restores skin pigmentation.

\section{Discussion}

The pathophysiology of vitiligo is not completely clear, although there is evidence of melanocyte loss from the cutaneous epidermis or dysfunction that loses the ability to secrete melanin. Therefore, the primary focus of treating vitiligo is to reverse the loss or hypoactivity of melanocytes, which is the basis of depigmentation. Kaliziri seeds have been used to treat skin pigmentation diseases in Central Asia for over a century. The seed extracts promoted tyrosinase activity and melanin production and induced the expression of melanogenesis-related proteins in the B16 melanoma cells. We found that CAM-Y7, a bioactive compound isolated from Kaliziri seed extracts, not only successfully accelerate melanogenesis in B16 cells, subsequently the mechanism of promoting effect on melanogenesis via p38 MAPK signal pathway to up-Regulation of MITF-induced Tyrosinase Expression, but also reversed HQ-induced depigmentation in C57BL/ 6 mice skin and hair by restoring tyrosinase activity and glutathione levels, and alleviating melanocyte apoptosis and melanosome degradation. In addition, CAM-Y7 also reversed the thickening of the epidermal stratum corneum induced by H.Q. and increased the number of melanic hair follicles. However, the C57BL/ 6 mice harbor numerous proliferative melanocytes in their hair follicles, which are the primary targets of H.Q. Therefore, HQ-induced depigmentation in the C57BL/ 6 mouse model mainly involves hair follicles and does not accurately simulate the epidermal changes seen in vitiligo ${ }^{[35]}$. To this end, we analyzed the effects of CAM-Y7 on the $\mathrm{H}_{2} \mathrm{O}_{2}$-treated brownish guinea pig model. The epidermal damage caused by $\mathrm{H}_{2} \mathrm{O}_{2}$ extends to the basal layer, eventually resulting in depigmentation closely resembling that in vitiligo. CAM-Y7 significantly alleviated $\mathrm{H}_{2} \mathrm{O}_{2}$-induced melanocyte damage and loss and restored melanin levels. Studies have implicated a localized increase in inflammatory cytokines in vitiligo induction and maintenance. For instance, both TNF- $a$ and IL- 6 have inhibitory effects on pigmentation, and TNF- $a$, in particular, facilitates keratinocyte apoptosis, eventually leading to melanocyte loss. The damage caused by $\mathrm{H}_{2} \mathrm{O}_{2}$ in the stratum corneum and deeper epidermal layers of guinea pig skin significantly increased IL- 6 and TNF- $a$, which CAM-Y7 alleviated. In addition, CAM-Y7 also acted as an antioxidant and protected the melanocytes from $\mathrm{H}_{2} \mathrm{O}_{2}$-induced oxidative damage, resulting in skin re-pigmentation. Taken together, these results suggest that CAM- $Y 7$ regulation of melanogenesis may be mediated by the activation of p38 MAPK and restored pigmentation in an HQInduced $\mathrm{C} 57 \mathrm{BL} / 6$ mouse and $\mathrm{H}_{2} \mathrm{O}_{2}$-induced guinea pig models of vitiligo (Figure 6).

\section{Conclusion}

CAM-Y7 regulation of melanogenesis may be mediated by the activation of p38 MAPK and restored pigmentation in an $\mathrm{HQ}$-Induced $\mathrm{C} 57 \mathrm{BL} / 6$ mouse and $\mathrm{H}_{2} \mathrm{O}_{2}$-induced guinea pig models of vitiligo. CAM-Y7 might be valuable and promising therapeutic as an agent for vitiligo. Subsequent clinical experiments using are needed to verify our results. 


\section{Declarations}

\section{Author contribution:}

Dr. Zulipiya Maimaiti, Ablajan Turak, Yuqin Luo, Xiaoling Ma, Haji Akber Aisa prepared the Chemical experiments, Dr. Nuramina Mamat, Haorong Li, Xueying Lu, for finished the study on Pharmacological experiments, and Dr. Deng Zang wrote the main manuscript text and data analysis.

\section{Funding}

Project supported by the National Key R\&D Program of China (Grant No. 2020YFE0205600). Funds of the West Light Foundation of The Chinese Academy of Science (2019-XBQNXZ-B-015).

\section{Availability of data and materials}

All data generated or analysed during this study are included in this published article and its ikmentary information files.

\section{Ethics approval and consent to participate}

The experiments were approved by the Institutional Ethical Committee for Laboratory of Xinjiang Medical University (Approval ID: SYXK-(xin) 2016-0002) and conducted following relevant guidelines and regulations. This study was carried out in compliance with the ARRIVE guidelines.

\section{Consent for publication}

All the authors have read the manuscript, and consent for publication.

\section{Competing interests}

The authors declare that they have no competing interests.

\section{References}

1. Riley, P.A., 1997. Melanin. Int J Biochem Cell Biol 29, 1235-1239.

2. Zokaei, S., Farhud, D.D., Keykhaei, M., Zarif Yeganeh, M., Rahimi, H., Moravvej, H., 2019. Cultured Epidermal Melanocyte Transplantation in Vitiligo: A Review Article. Iran J Public Health 48, 388-399.

3. Ding, X., Mei, E., Hu, M., Zhou, C., Li, X., Cai, L., Li, Z., 2019. Effect of puerarin on melanogenesis in human melanocytes and vitiligo mouse models and the underlying mechanism. Phytother Res 33 , 205-213.

4. Smith, M.P., Ly, K., Thibodeaux, Q., Bhutani, T., Nakamura, M., 2019. Home phototherapy for patients with vitiligo: challenges and solutions. Clin Cosmet Investig Dermatol 12, 451-459. 
5. del Marmol, V., Beermann, F., 1996. Tyrosinase and related proteins in mammalian pigmentation. FEBS Lett 381, 165-168.

6. Hsu, C.H., Liou, G.G., Jiang, Y.J., 2019. Nicastrin Deficiency Induces Tyrosinase-dependent Depigmentation and Skin Inflammation. J Invest Dermatol.

7. Ishikawa, M., Kawase, I., Ishii, F., 2007. Glycine inhibits melanogenesis in vitro and causes hypopigmentation in vivo. Biol Pharm Bull 30, 2031-2036.

8. Vachtenheim, J., Borovanský, J., 2010. "Transcription physiology" of pigment formation in melanocytes: central role of MITF. Exp Dermatol 19, 617-627.

9. Bentley, N.J., Eisen, T., Goding, C.R., 1994. Melanocyte-specific expression of the human tyrosinase promoter: activation by the microphthalmia gene product and role of the initiator. Mol Cell Biol 14, 7996-8006.

10. Kaur, K., Kaur, R., Bala, I., 2019. Therapeutics of premature hair graying: A long journey ahead. J Cosmet Dermatol.

11. Saha, B., Singh, S.K., Sarkar, C., Bera, R., Ratha, J., Tobin, D.J., Bhadra, R., 2006. Activation of the Mitf promoter by lipid-stimulated activation of p38-stress signalling to CREB. Pigment Cell Res 19, 595605.

12. Tuerxuntayi, A., Liu, Y.Q., Tulake, A., Kabas, M., Eblimit, A., Aisa, H.A., 2014. Kaliziri extract upregulates tyrosinase, TRP-1, TRP-2 and MITF expression in murine B16 melanoma cells. BMC Complement Altern Med 14, 166.

13. Kim, A., Yim, N.H., Im, M., Jung, Y.P., Liang, C., Cho, W.K., Ma, J.Y., 2013. Ssanghwa-tang, an oriental herbal cocktail, exerts anti-melanogenic activity by suppression of the p38 MAPK and PKA signaling pathways in B16F10 cells. BMC Complement Altern Med 13, 214.

14. Hu, D.N., 2008. Methodology for evaluation of melanin content and production of pigment cells in vitro. Photochem Photobiol 84, 645-649.

15. Natale, C.A., Duperret, E.K., Zhang, J., Sadeghi, R., Dahal, A., O'Brien, K.T., Cookson, R., Winkler, J.D., Ridky, T.W., 2016. Sex steroids regulate skin pigmentation through nonclassical membrane-bound receptors. Elife 5.

16. Zang, D., Niu, C., Aisa, H.A., 2019. Amine derivatives of furocoumarin induce melanogenesis by activating Akt/GSK-3beta/beta-catenin signal pathway. Drug Des Devel Ther 13, 623-632.

17. Huo, S.X., Wang, Q., Liu, X.M., Ge, C.H., Gao, L., Peng, X.M., Yan, M., 2017. The Effect of Butin on the Vitiligo Mouse Model Induced by Hydroquinone. Phytother Res 31, 740-746.

18. Na, J.I., Shin, J.W., Choi, H.R., Kwon, S.H., Park, K.C., 2019. Resveratrol as a Multifunctional Topical Hypopigmenting Agent. Int J Mol Sci 20.

19. Jow, T., Hantash, B.M., 2014. Hydroquinone-induced depigmentation: case report and review of the literature. Dermatitis 25, e1-5.

20. Tse, T.W., 2010. Hydroquinone for skin lightening: safety profile, duration of use and when should we stop? J Dermatolog Treat 21, 272-275. 
21. Gupta, A.K., Gover, M.D., Nouri, K., Taylor, S., 2006. The treatment of melasma: a review of clinical trials. J Am Acad Dermatol 55, 1048-1065.

22. Ogbechie-Godec, O.A., Elbuluk, N., 2017. Melasma: an Up-to-Date Comprehensive Review, Dermatol Ther (Heidelb), 2017/07/21 ed, pp. 305-318.

23. Shi, H.X., Zhang, R.Z., Xu, B., Xu, C.X., Li, D., Wang, L., Xiao, L., 2019. Experimental study and clinical observations of autologous hair follicle cell transplants to treat stable vitiligo. Indian J Dermatol Venereol Leprol.

24. Karunarathne, W., Molagoda, I.M.N., Kim, M.S., Choi, Y.A.-O., Oren, M., Park, E.A.-O., Kim, G.A.-O., Flumequine-Mediated Upregulation of p38 MAPK and JNK Results in Melanogenesis in B16F10 Cells and Zebrafish Larvae. LID - 10.3390/biom9100596 [doi] LID - 596

25. Harris, J.E., Harris, T.H., Weninger, W., Wherry, E.J., Hunter, C.A., Turka, L.A., 2012. A mouse model of vitiligo with focused epidermal depigmentation requires IFN-gamma for autoreactive CD8(+) T-cell accumulation in the skin. J Invest Dermatol 132, 1869-1876.

26. Lee, T.H., Seo, J.O., Baek, S.H., Kim, S.Y., 2014. Inhibitory effects of resveratrol on melanin synthesis in ultraviolet B-induced pigmentation in Guinea pig skin. Biomol Ther (Seoul) 22, 35-40.

27. Basak, P.Y., Adiloglu, A.K., Ceyhan, A.M., Tas, T., Akkaya, V.B., 2009. The role of helper and regulatory T cells in the pathogenesis of vitiligo. J Am Acad Dermatol 60, 256-260.

28. Moretti, S., Fabbri, P., Baroni, G., Berti, S., Bani, D., Berti, E., Nassini, R., Lotti, T., Massi, D., 2009. Keratinocyte dysfunction in vitiligo epidermis: cytokine microenvironment and correlation to keratinocyte apoptosis. Histol Histopathol 24, 849-857.

29. Moretti, S., Spallanzani, A., Amato, L., Hautmann, G., Gallerani, I., Fabiani, M., Fabbri, P., 2002. New insights into the pathogenesis of vitiligo: imbalance of epidermal cytokines at sites of lesions. Pigment Cell Res 15, 87-92.

30. Picardo, M., Dell'Anna, M.L., Ezzedine, K., Hamzavi, I., Harris, J.E., Parsad, D., Taieb, A., 2015. Vitiligo. Nat Rev Dis Primers 1, 15011.

31. Schallreuter, K.U., Moore, J., Wood, J.M., Beazley, W.D., Gaze, D.C., Tobin, D.J., Marshall, H.S., Panske, A., Panzig, E., Hibberts, N.A., 1999. In vivo and in vitro evidence for hydrogen peroxide (H2O2) accumulation in the epidermis of patients with vitiligo and its successful removal by a UVB-activated pseudocatalase. J Investig Dermatol Symp Proc 4, 91-96.

32. Wood, J.M., Decker, H., Hartmann, H., Chavan, B., Rokos, H., Spencer, J.D., Hasse, S., Thornton, M.J., Shalbaf, M., Paus, R., Schallreuter, K.U., 2009. Senile hair graying: H2O2-mediated oxidative stress affects human hair color by blunting methionine sulfoxide repair. Faseb j 23, 2065-2075.

33. Enguita, F.J., Leitao, A.L., 2013. Hydroquinone: environmental pollution, toxicity, and microbial answers. Biomed Res Int 2013, 542168.

34. Inayat-Hussain, S.H., Ibrahim, H.A., Siew, E.L., Rajab, N.F., Chan, K.M., Williams, G.T., Ross, D., 2010. Modulation of the benzene metabolite hydroquinone induced toxicity: evidence for an important role of fau. Chem Biol Interact 184, 310-312. 
35. van den Boorn, J.G., Konijnenberg, D., Dellemijn, T.A., van der Veen, J.P., Bos, J.D., Melief, C.J., VythDreese, F.A., Luiten, R.M., 2009. Autoimmune destruction of skin melanocytes by perilesional T cells from vitiligo patients. J Invest Dermatol 129, 2220-2232.

\section{Figures}

A.

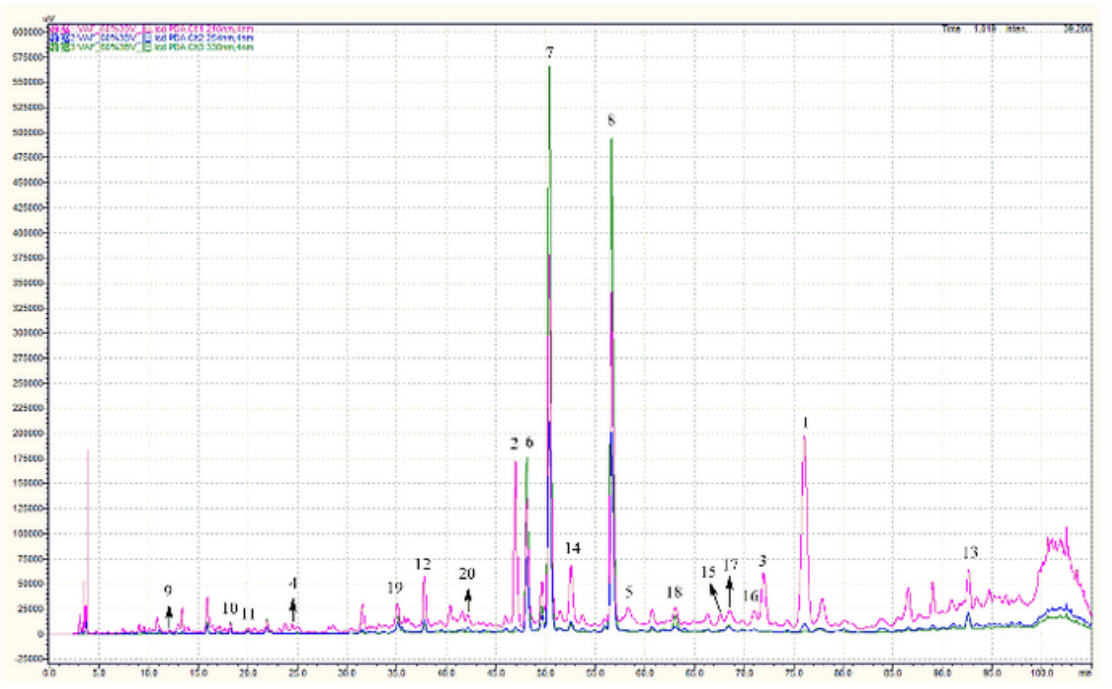

B.
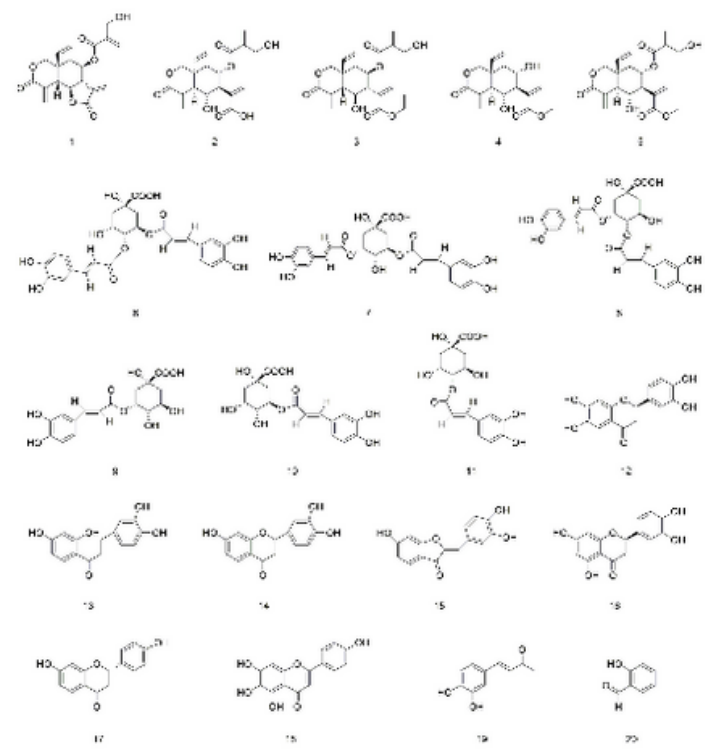

\section{Figure 1}

Characterization of drug components restores pigmentation of murine epidermis hair exposed to H.Q. (A) HPLC chromatogram of the Kaliziri standard Extracts (CAM-Y7). Pink - $210 \mathrm{~nm}$, blue - $254 \mathrm{~nm}$, green $330 \mathrm{~nm}$. (1) vernodalin, (2) 3,5-0-dicaffeoylquinic acid, (3) 4,5-0-dicaffeoylquinic acid, (4) 3,4-0-

dicaffeoylquinic acid, (5) vernodalinol, (6) butein, (7) 5-0- caffeoylquinic acid, (8) 3-0-caffeoylquinic acid, and (9) 4-0-caffeoylquinic acid (B) The structures of the 20 compounds. 
A.

NC
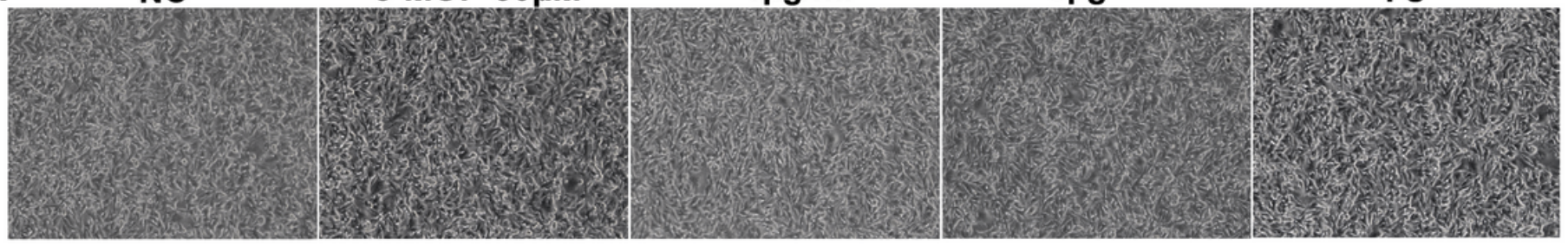

B.

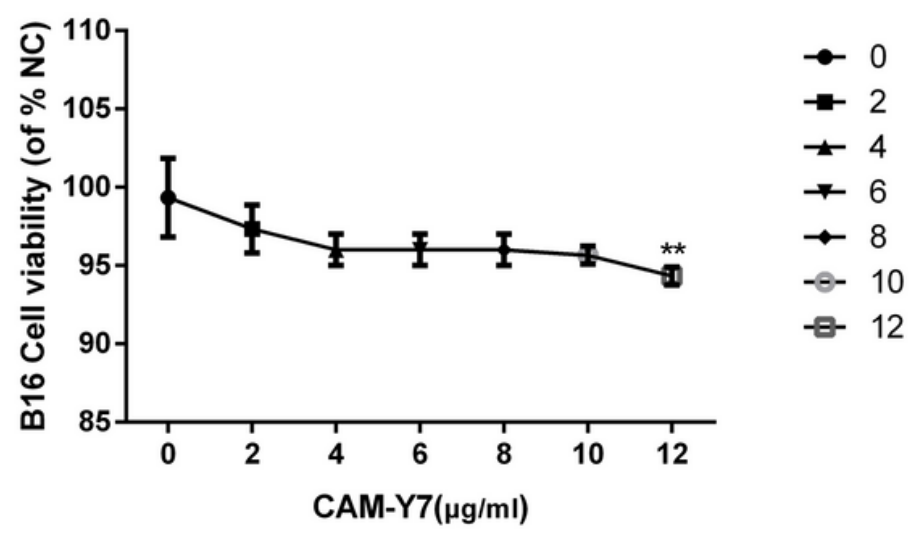

C.

D.

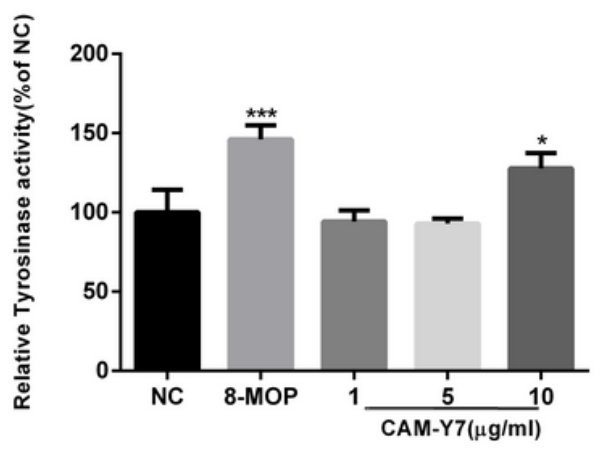

E.

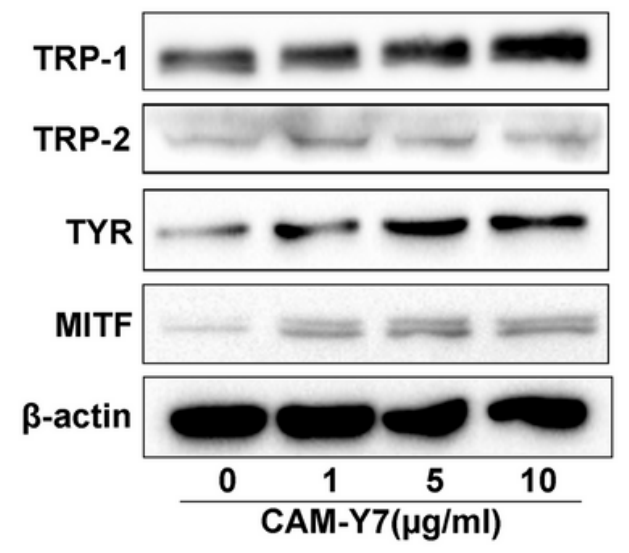

F.

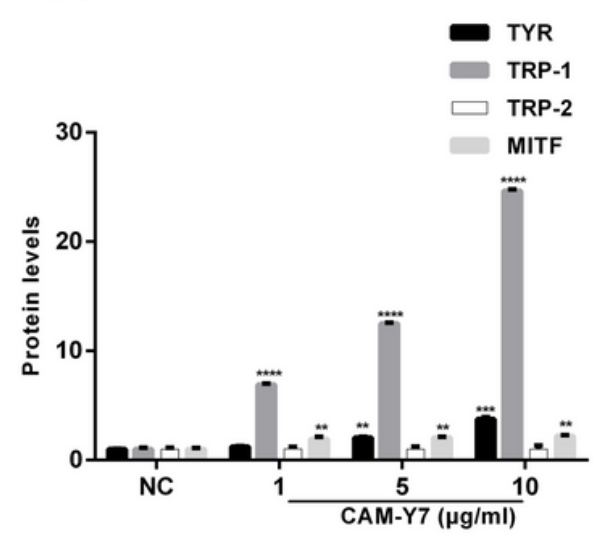

Figure 2

CAM-Y7 promotes melanogenesis in B16 cells (A). Morphological changes in CAM-Y7 treated B16 cells at 200x magnification. (B). Different concentrations $(0-12 \mu \mathrm{g} / \mathrm{ml})$ of CAM-Y7 on B16 cell viability were measured by CCK-8 assay. The data are expressed as the mean \pm S.D. ( $* \star P<0.01$ compared to DMSO $(0.1 \%)$ vehicle group). (C). Effect of CAM-Y7 on melanin content in B16 melanoma cells. Cells were treated with different concentrations $(0,1,5$ and $10 \mu \mathrm{g} / \mathrm{ml})$ of CAM-Y7 for $72 \mathrm{~h} .{ }^{*} \mathrm{p}<0.05$, ${ }^{\star \star \star} \mathrm{p}<0.001$ compared to DMSO (0.1\%) group. (D). Tyrosinase activity in the similarly treated B16 melanoma cells. DMSO $(0.1 \%)$ was used as the vehicle control and 8-MOP $(50 \mu \mathrm{M})$ positive control. Results are expressed as mean \pm S.D. ${ }^{*} p<0.05,{ }^{\star \star \star} p<0.001$ compared to DMSO (0.1\%) group. (E). Effect of CAM-Y7 on the expression of melanogenic genes. B16 cells were treated with different concentrations $(0-10 \mu \mathrm{g} / \mathrm{ml})$ of CAM-Y7 for 48h, and expression levels of MITF, TYR, TRP-1, and TRP-2 proteins were evaluated by Western blotting. (F). The Quantity One program measured the band densities of proteins, and the expression levels of each protein were normalized against $\beta$-actin expression. The data were shown as 
mean \pm S.D. and analyzed by one-way analysis of variance (ANOVA) followed by Turkey's test. $* \star<0.01$, ${ }^{* \star *} p<0.001,{ }^{*} * \star p<0.0001$ compared to control group. All experiments were performed three times.

A.
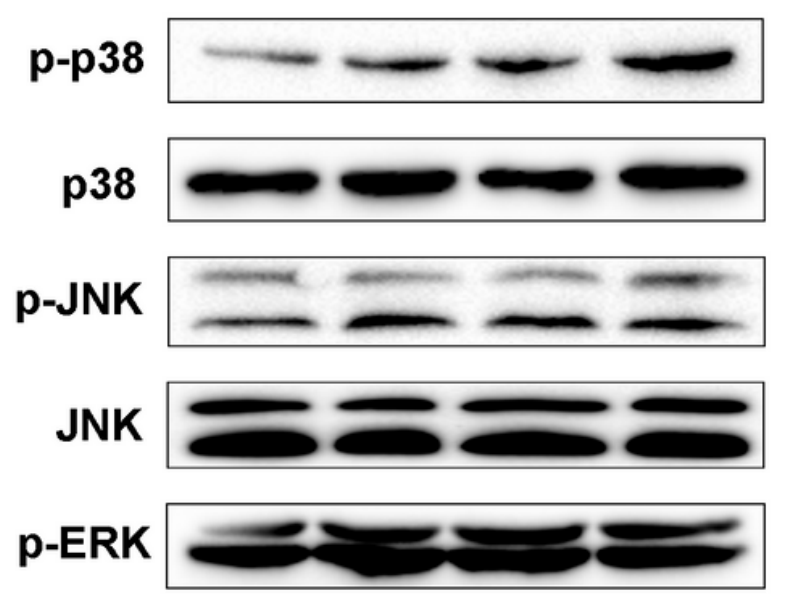

\section{ERK}

$\beta$-actin
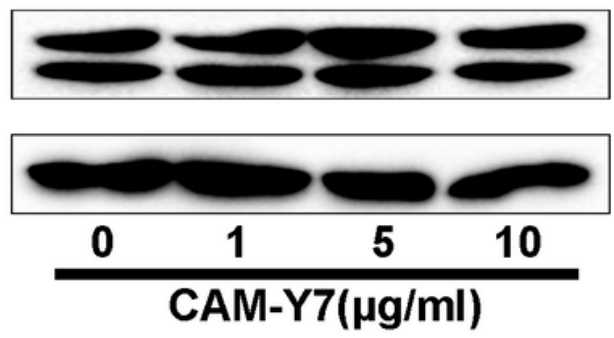

B.

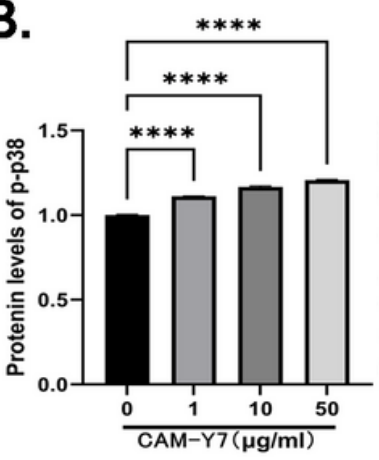

C.
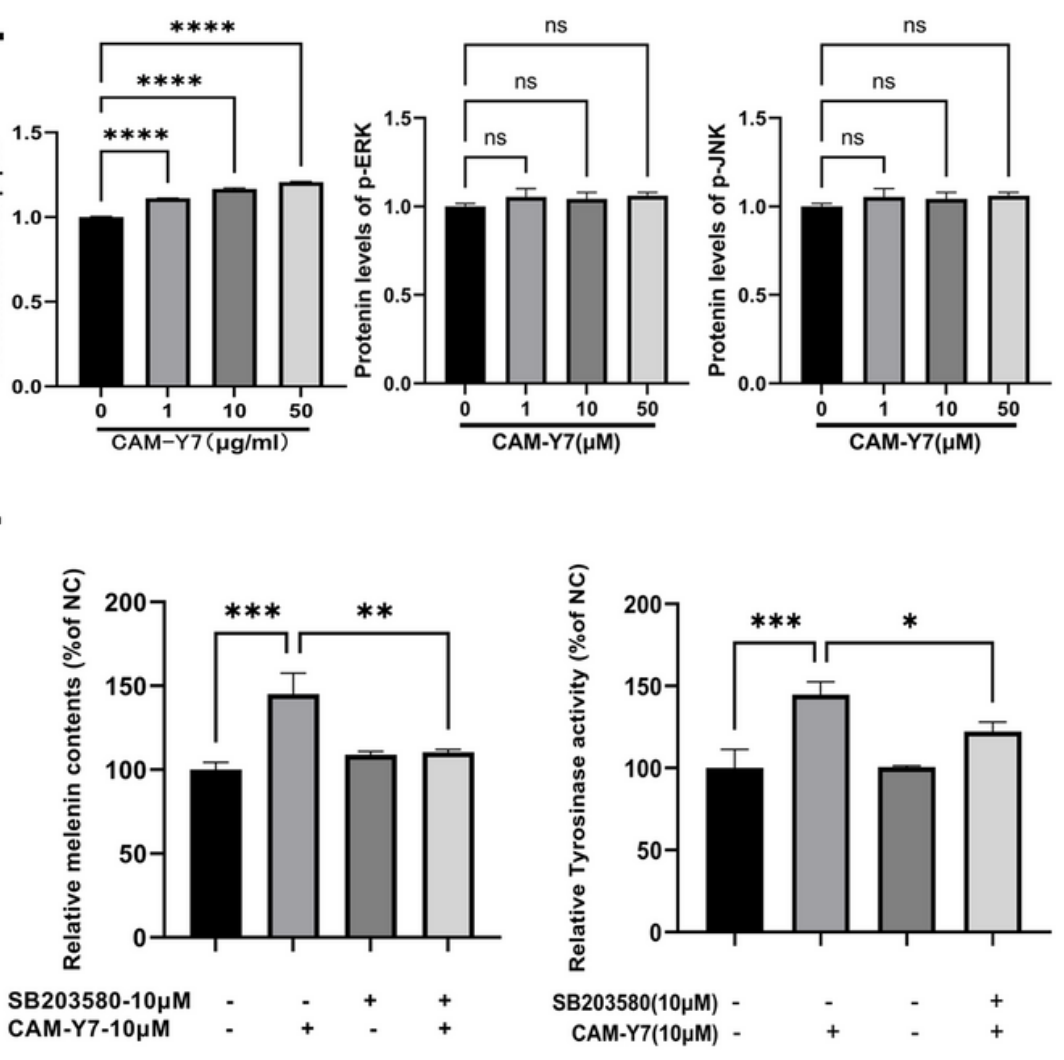

Figure 3

CAM-Y7 activates the p38 MAPK signaling pathway. (A) p-p38, p38, p-JNK, JNK, p-ERK, and ERK protein levels were analyzed by Western blotting. $\beta$-actin served as an internal control. (B) The Quantity One program measured the band densities of proteins, and the expression levels of each protein were normalized against $\beta$-actin expression. The data were shown as mean \pm S.D. and analyzed by one-way analysis of variance (ANOVA) followed by Turkey's test. ${ }^{\star} * \star x p 0.0001$ compared to the control group. All experiments were performed three times. (C) Effects of CAM-Y7 and SB203580 on melanogenesis and Tyrosinase in B16 cells. B16 cells were treated with $10 \mu \mathrm{g} / \mathrm{mL}$ of CAM-Y7 or $10 \mu \mathrm{M} \mathrm{SB203580} \mathrm{(p38}$ inhibitor) for $48 \mathrm{~h}$. The data were shown as mean \pm S.D. and analyzed by one-way analysis of variance (ANOVA) followed by Turkey's test. ${ }^{* \star} p<0.001$ compared to the control group, ${ }^{*} p<0.05,{ }^{* \star} p<0.01$ compared to the CAM-Y7 group. 
A.
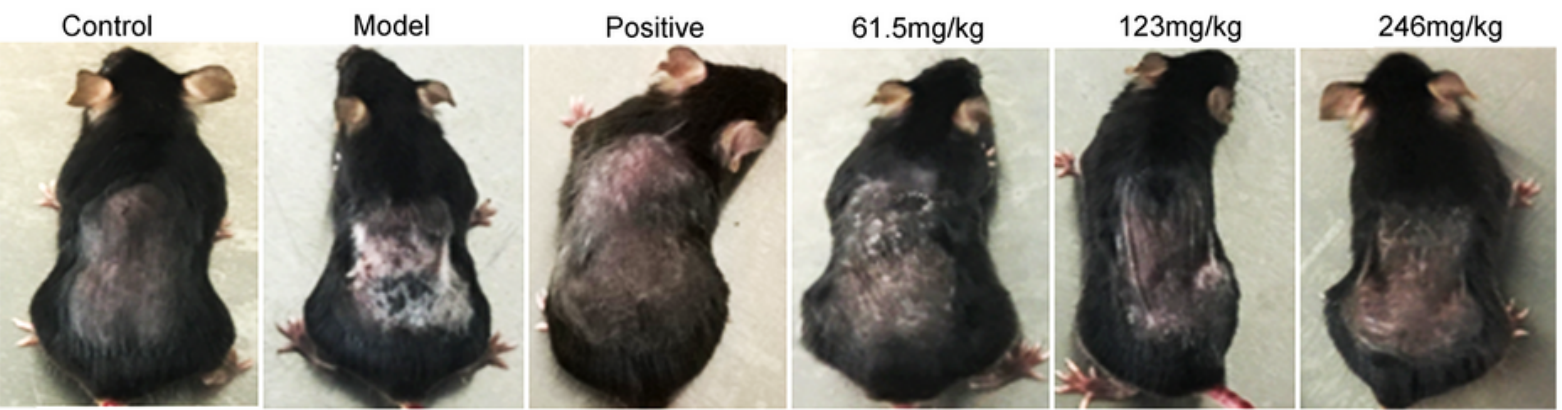

B.

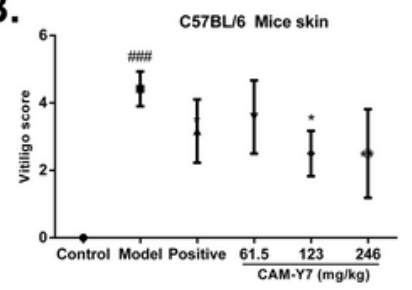

c.

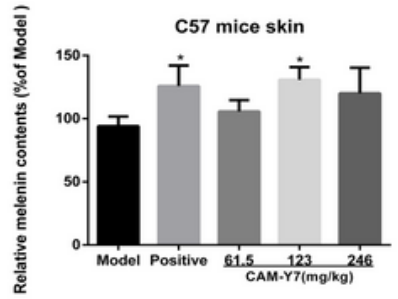

D.
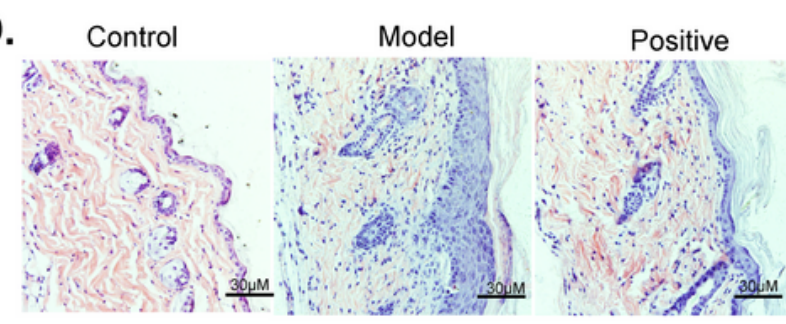

$61.5 \mathrm{mg} / \mathrm{kg}$
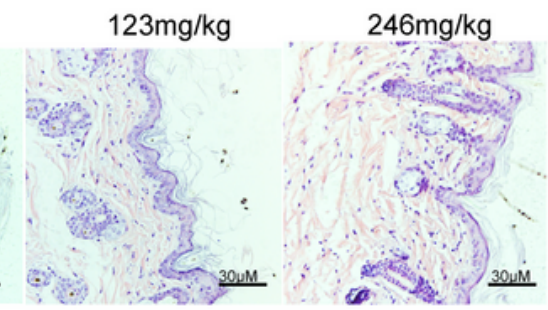

E.
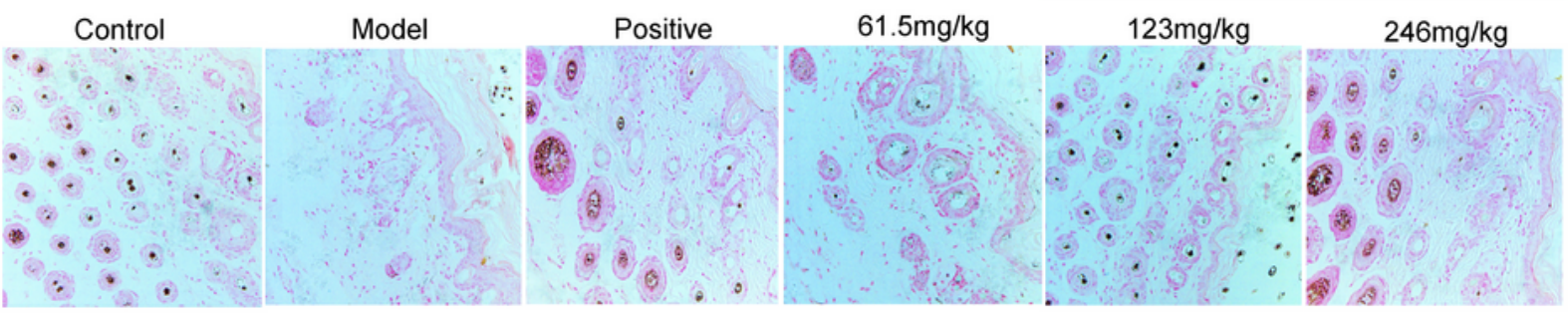

F.
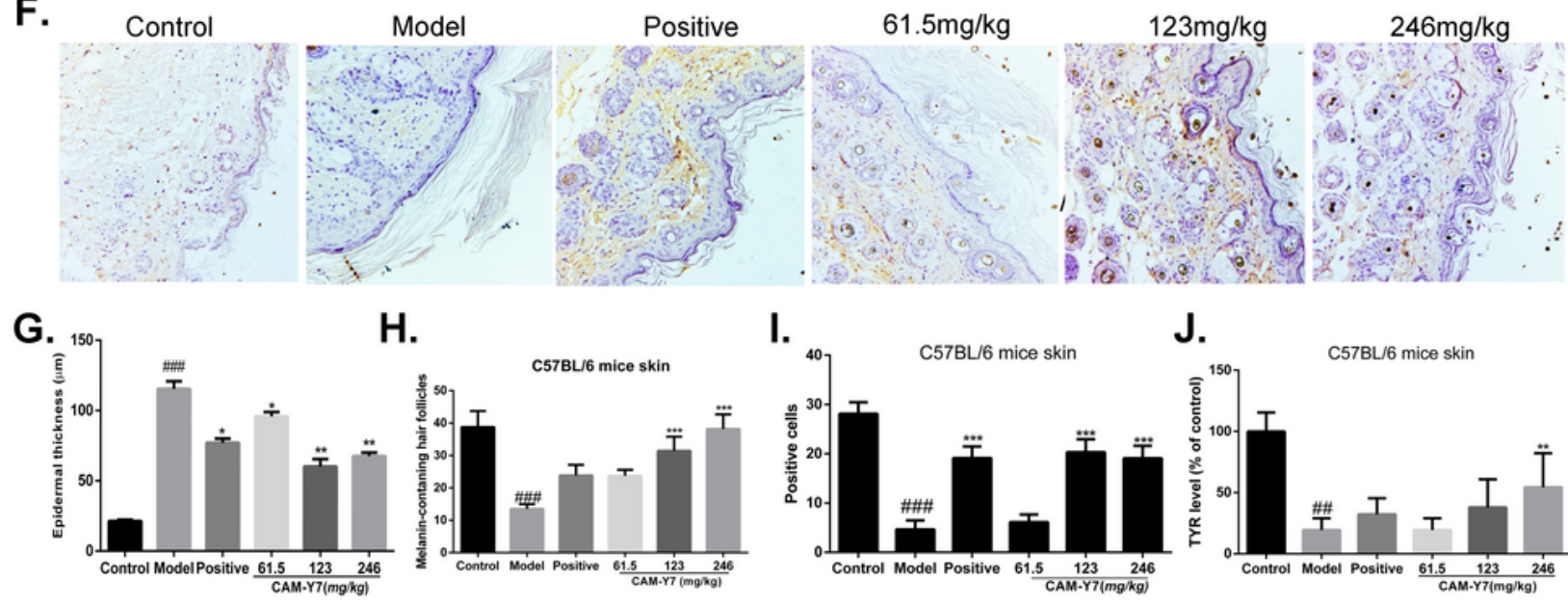

H.

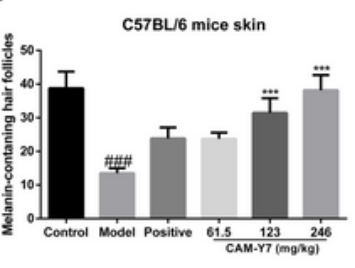

I.

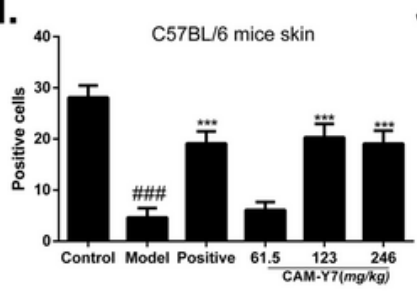

J.

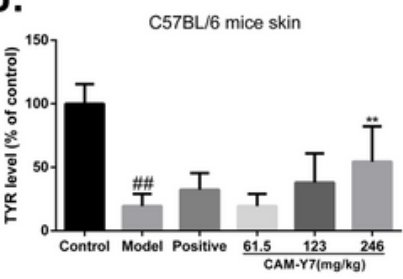

Figure 4

CAM-Y7 restores melanogenesis in hydroquinone (H.Q.)-induced Vitiligo mouse model by promoting Tyrosinase expression (A) Representative images of mice after 30 days of CAM-Y7 treatment showing the extent of dorsal depigmentation. (B) The scatter plot shows average vitiligo scores (right, upper panel), and the bar graph compares melanin content in all groups (right, lower panel). ( $\mathrm{n}=10$ mice per group). \#\#\#p<0.001 compared to control group, ${ }^{*} \mathrm{p}<0.05$ compared to HQ model group. (C) Melanin content in 
skin tissue treated with different concentrations $(61.5,123$, and $246 \mathrm{mg} / \mathrm{kg})$ CAM-Y7. one-way ANOVA $p<0.0001$ with Tukey's, $*<0.05$ compared to hydroquinone model group. (D) Representative crosssectional images of HE-stained murine skin samples of the differentially-treated mice (magnification $200 x$, scale bar $-30 \mu m, n=10$ per group), (G) and quantification of an epidermal thickness (right). \#\#\#p<0.001 compared to control group, ${ }^{*} p<0.05$, ${ }^{*} p<0.01$ compared to HQ model group. (E) Representative images of dorsal skin sections showing Lillie-stained melanin-containing hair follicles (magnification $-200 x, n=10$ per group), $(H)$ and quantification of the melanic hair follicles. \#\#\#p<0.001 compared to control group, ${ }^{\star \star \star} \mathrm{p}<0.001$ compared to $\mathrm{HQ}$ model group. (F) Representative images of the differentially-treated mice's dorsal skin show in situ tyrosine staining (magnification $-200 x, n=10$ per group), (I) and quantification of positive cells. \#\#\#p<0.001 compared to control group, $\star \star \star p<0.001$ compared to HQ model group. (J) Bar graphs comparing the epidermal TYR levels (by ELISA). \#\#p<0.01 compared to control group, ${ }^{\star \star} \mathrm{p}<0.01$ compared to $\mathrm{HQ}$ model group. 


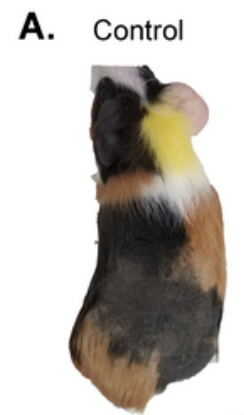

B.
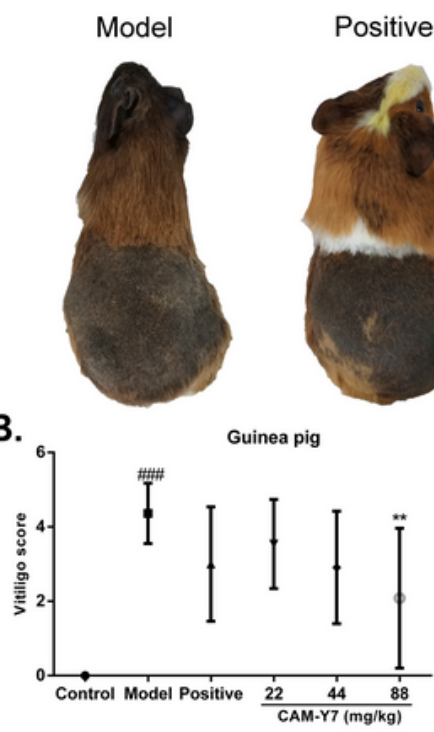
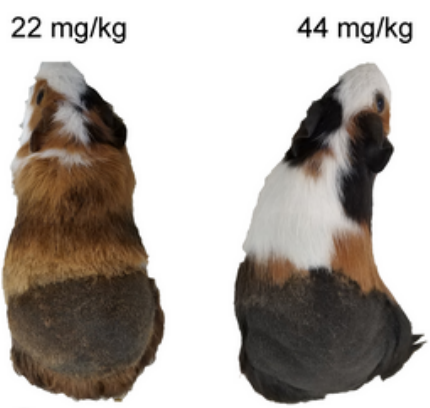

$88 \mathrm{mg} / \mathrm{kg}$

C.

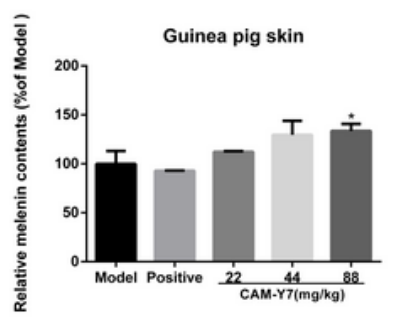

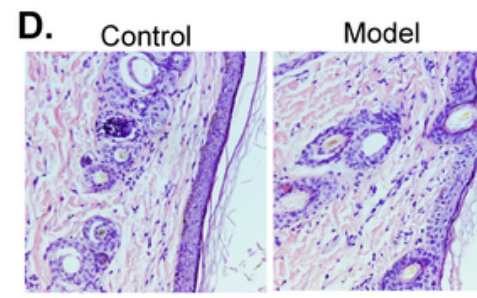

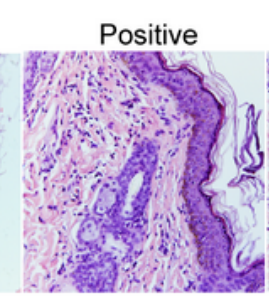

$44 \mathrm{mg} / \mathrm{kg}$

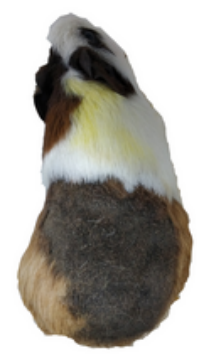

E. Control

Model

Positive

$22 \mathrm{mg} / \mathrm{kg}$
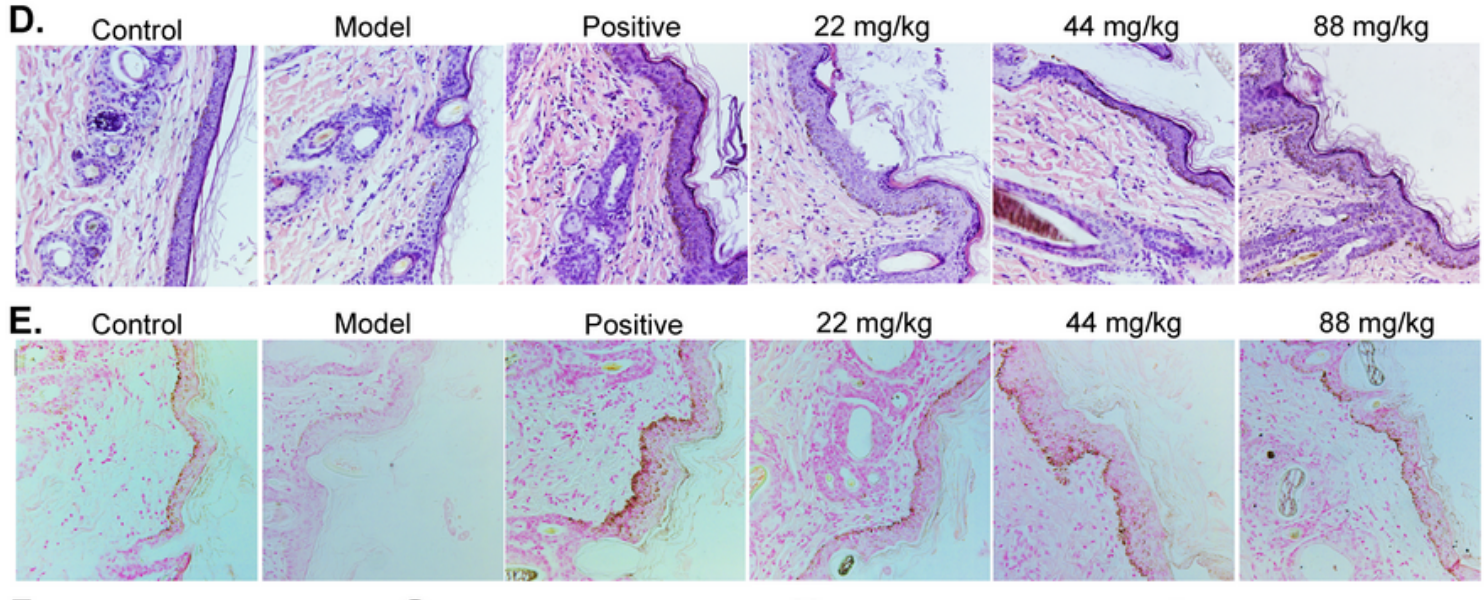

F.

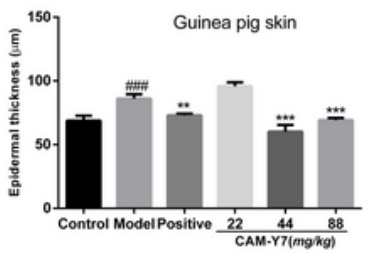

J.

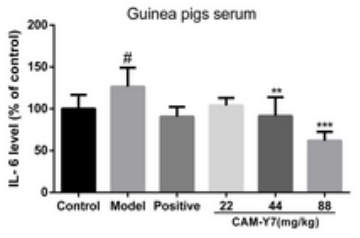

G.

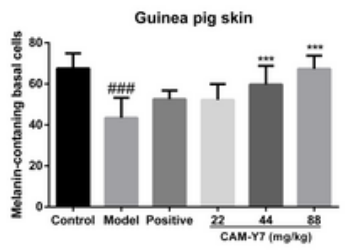

K.

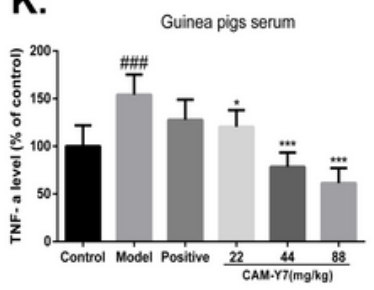

$44 \mathrm{mg} / \mathrm{kg}$

$88 \mathrm{mg} / \mathrm{kg}$

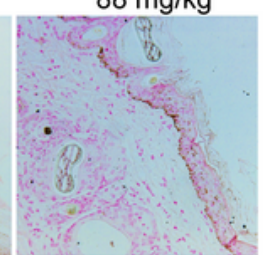

H.

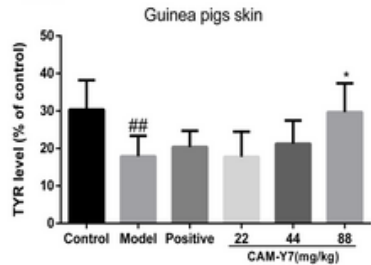

L.

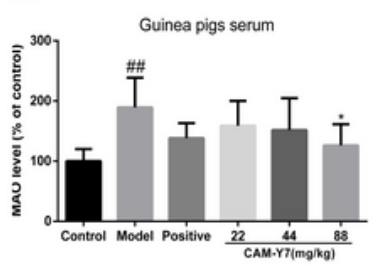

I.

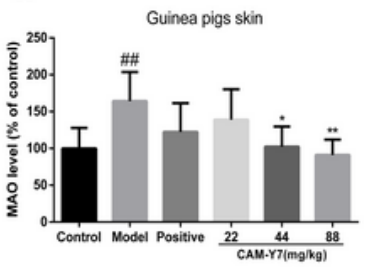

M.

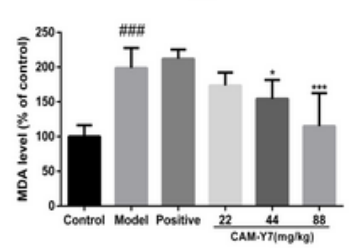

\section{Figure 5}

CAM-Y7 restores H2O2-induced depigmentation of guinea pig skin. (A) Representative images of guinea pigs after 30 days of CAM-Y7 treatment showing the extent of depigmentation. (B) Vitiligo scores of the different groups after 30 days of treatment ( $n=10$ guinea pigs per group). \#\#\#p<0.001 compared to control group, ${ }^{\star \star} \mathrm{p}<0.01$ compared to $\mathrm{H} 2 \mathrm{O} 2$ model group. (C). Melanin content in the skin samples of different groups. $*<0.05$ compared to the hydroquinone model group. (D) Representative cross-sectional 
images of HE-stained guinea pig dorsal skin (magnification $-200 x, n=10$ per group, scale bar $-30 \mu m$ ). (F) Quantification of epidermal thickness. \#\#\#p<0.001 compared to control group, ${ }^{\star \star} p<0.01,{ }^{\star \star *} p<0.001$ compared to $\mathrm{H} 2 \mathrm{O} 2$ model group. (E) Representative images of Lillie-stained guinea pig skin sections showing melanin granules (magnification $-200 x, n=10$ per group), (G)and quantification of melanincontaining basal cells. \#\#\#p<0.001 compared to control group $* \star * p<0.001$ compared to $\mathrm{H} 2 \mathrm{O} 2$ model

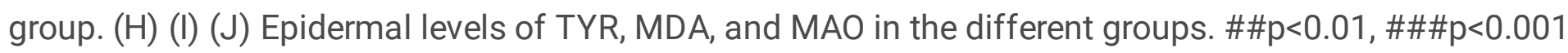
compared to control group, ${ }^{\star} p<0.05,{ }^{*} \mathrm{p}<0.01$, ${ }^{\star} \mathrm{p}<0.001$ compared to $\mathrm{H} 2 \mathrm{O} 2$ model group. (K) (L)(M)

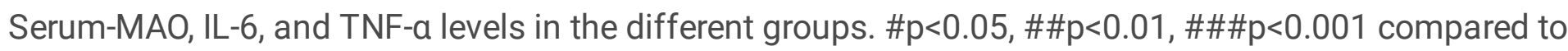
control group, ${ }^{*} \mathrm{p}<0.05,{ }^{*} \mathrm{p}<0.01, * * \star \mathrm{p}<0.001$ compared to $\mathrm{H} 2 \mathrm{O} 2$ model group.

\section{Supplementary Files}

This is a list of supplementary files associated with this preprint. Click to download.

- WesternBlotoriginalband.pdf

- OnlineGraphicalabstract.png 